\title{
A Comparative Study on Gender Agreement Errors in the Spoken Spanish of Heritage Speakers and Second Language Learners
}

\author{
Elizabeth A. MartineZ-Gibson \\ Dept. of Hispanic Studies \\ College of Charleston, USA
}

Received: 5 April 2010 / Accepted: 10 August 2010

ISSN: $1697-7467$

\begin{abstract}
This study analyzes grammatical gender errors in the spoken Spanish of three groups of high school students in the United States: first and second generation heritage speakers and second language learners; and compares the findings to previous research in the areas of second language acquisition and language of heritage speakers in a contact situation. Students were presented with a series of drawings with questions related to social settings. The responses were recorded and analyzed for differences in the number of gender assignment and agreement errors between the three different groups and in the error patterns of gender assignment and agreement provided by these groups.
\end{abstract}

Keywords: Language in contact; second language acquisition; heritage speakers; minority languages; bilingualism; first language attrition and Spanish in the United States.

Estudio comparado sobre errores de concordancia de género en el español hablado por estudiantes de español como lengua hereditaria y segunda lengua

RESUMEN: Este estudio analiza los errores de género gramatical en el español hablado de tres grupos de estudiantes de la escuela secundaria en los Estados Unidos: la primera y segunda generación de hispanohablantes y estudiantes de español como segunda lengua; y compara los resultados con estudios previos sobre la adquisición de la lengua secundaria y la primera lengua de los hablantes en una situación de contacto de lenguas. A los estudiantes se les presentó una serie de dibujos con cuestionarios de situaciones sociales. Se grabaron las respuestas y se analizaron las diferencias en el número y los tipos de errores de género asignado a los sustantivos y de concordancia entre el sustantivo y el adjetivo presentadas por los tres grupos de hispanohablantes. Palabras claves: Lenguas en contacto; adquisición de lenguas extranjeras; hispanohablantes; lenguas de minorías; bilingüismo; pérdida de la lengua nativa y el español de los Estados Unidos.

\section{INTRODUCTION}

Linguists have been studying the complexity of grammatical gender systems in languages such as Spanish, French, German and others for some time. The main areas of interest address early age L1 gender acquisition (Karmiloff-Smith, 1979; Pérez-Pereira, 1991; and Müeller, 
1994), L2 gender acquisition (Finnemann, 1992; Hawkins, 1998; Fernández-García, 1999; Bruhn de Garavito \& White, 2000; Alarcón, 2004; and Montrul, 2006), gender acquisition in bilinguals (Lipski, 1993; Anderson, 1999; Montrul, 2006; and Zaretsky \& Bar-Shalom, 2008) and, more recently, gender acquisition in heritage speakers versus second language learners (Montrul, Foote \& Perpiñán, 2008 and Polinsky, 2008). Some of the latest studies have focused on the similarities of language acquisition between the heritage speakers' L1 and the L2 speakers (Montrul, 2002, 2004, 2006; and Polinsky, 2006, 2008).

The present study analyzes the error patterns in gender assignment and agreement of nouns and their modifiers in second language learners and two groups of heritage speakers (designated first and second generation) of Spanish in the United States.

\section{Grammatical gender in SPANish}

To proceed with this study, it is important to understand that in Spanish, gender is reflected through its morphological and/or syntactic system. Each noun is assigned gender (masculine or feminine) through a series of specific grammatical rules that at times present exceptions.

In some cases, gender is reflected by its lexical category, that is, if the noun refers to a person, it will be masculine or feminine respectively (el hombre 'the man' versus la mujer 'the woman'). In other cases, nouns manifest gender with the use of morphemes. For example, most nouns ending in $-o$, such as el libro (the book), are designated as masculine; while those ending in $-a$, such as la silla (the chair), are feminine. Others have inflectional morphemes where the final $-o$ changes to $-a$ to reflect the change from a masculine to a feminine gender. This occurs particularly when referring to a person (i.e. el niño 'the boy' versus la niña 'the girl'). A number of nouns present patterns with derivational morphemes, associating them with one of the two genders. This is the case of nouns ending in -ción,-sión,-tad or -dad, which are feminine (la nación 'the nation'); or those that end in $-z,-n$, or $-r$, which are mostly masculine (el pez 'the fish' or el algodón 'the cotton'). Yet others, ending in $-e$ or other consonants reflect gender through their modifiers, such as an article (el coche 'the car' or una pared 'a wall').

Nevertheless, with this series of common rules for gender assignment there are exceptions. For example, whereas nouns ending in $-z$ are mostly masculine, i.e. el lápiz (the pencil), there are exceptions such as la vez (the time/instance), which is feminine. Other exceptions include words of Greek origin. For instance, el problema (the problem), ending in $-a$, is a masculine noun or la mano (the hand), ending in $-o$, is feminine. An additional obstacle that may cause confusion in assigning gender relates to phonetics. When learning the gender of nouns many students are taught to learn the noun with its appropriate definite article, i.e. el/la (the); but when a singular feminine noun with an initial stressed $a$ - such as agua (water) is accompanied by an article, the masculine form of the article (el agua 'the water' and not *la agua) is used for phonological reasons. This only occurs in the singular form and only with articles, not with adjectives or other modifiers (las águilas 'the eagles' or el agua fría 'cold water') adding to the confusion of gender assignment and agreement.

The understanding of the gender system for Spanish nouns is an issue of gender assignment and gender agreement, which entails syntax. Adjectives with inflectional morphemes such as 
$-O$ and $-a$ will agree in gender with the noun they describe, for example, la casa bonita (the nice house). For the Spanish language learner whose L1 does not distinguish noun gender, i.e. English, assigning gender markers to all noun modifiers may be viewed as redundant and may account for errors.

\section{Previous studies}

There have been countless studies focusing on the grammatical gender systems of different languages and their acquisition by diverse groups of first and second language learners. As the present study analyzes errors in noun gender assignment and agreement of heritage speakers and second language learners, this section will address previous studies in both of these areas.

\subsection{Second language learners}

Recent studies have concentrated on two topics related to the acquisition of grammatical gender in second language learners, both of which are associated with the present study. The first topic addresses the role that the L1 may have on L2 acquisition; and the second investigates the L2 learners' use of a default gender for nouns evidenced in a number of studies.

Clahsen and Muysken's (1989) no parameter setting hypothesis suggests that L2 learners have access to Universal Grammar principles via their L1, but are limited to those settings. Therefore, if grammatical gender does not exist in the L1, it is unattainable in the L2. Similar claims are made with Hawkins and Chan's (1997) failed functional features hypothesis. The following studies set out to test these hypotheses.

In his 1998 study, Hawkins observed gender agreement between nouns and their determiners in ten advanced L2 French learners with L1 English. The students were in their last year at university and had studied in France for six months. The task was to watch an animated film and give an oral description of what happened. The data was analyzed for definite and indefinite articles, as well as adjective agreement. In his results, Hawkins found that overall his subjects were accurate with gender agreement; there was greater accuracy with definite articles versus indefinite articles; and there was an apparent default gender with articles, leading to one particular gender over another, i.e. masculine or feminine. However, the default gender varied from one individual to another. Hawkins attributed his findings to the absence of grammatical gender in English justifying his failed features hypothesis (Hawkins and Chan 1997).

In a similar study, Bruhn de Garavito and White (2000) analyzed gender agreement in L1 French teenagers with one or two years of classroom exposure to L2 Spanish. In an oral interview, subjects were asked to describe pictures. Despite a difference in proficiency levels (lower versus advanced levels) between Hawkin's (1998) study and this one, the results were comparable: a high rate of accuracy observing more problems with indefinite versus definite articles; and the assignment of a default gender. Although it may seem beneficial if both the L1 and the L2 have grammatical gender, the similarities in the results of these two studies with different L1 populations suggest otherwise.

Sabourin (2001) aimed to test the effects that the L1 had on grammatical gender in the L2. Her subjects included L2 Dutch speakers with L1 German; Romance language and English speakers; and a native speaker control group. The task involved decision making on agreement 
between nouns and their articles, adjectives and pronouns. Sabourin's results indicated that none of the groups performed at the level of the native-speaker control group; and out of the three remaining groups the L1 German speakers performed most accurately; followed by the Romance language speakers; and finally the English speakers. In her results, she suggested that both the presence and absence of gender in the L1 had an effect on L2 gender.

White et al (2001) studied the effect of L1 on L2 acquisition of gender and number. Their subjects included L2 Spanish learners of L1 French and L1 English speakers at three different levels of proficiency, and a native Spanish-speaking control group. One of the tasks included identifying pictures related to a sentence in a story provided. Based on gender and number agreement, subjects had to select the one picture that identified the referent in the sentence. The other task was a vocabulary test to ensure that subjects had the relevant vocabulary to complete the task. The results indicated a difference between the three levels of proficiency. The lower proficiency level had an advantage of L1 French over L1 English, but the intermediate and advanced speakers of these two L1 groups were equally accurate; and they were comparable to the native Spanish-speaking control group. The researchers attributed the L1 effects on L2 acquisition of the lower-level proficiency group to the use of an interlanguage grammar; and concluded that L2 learners were not restricted to functional features present in their L1.

In addition to whether L1 plays a role in L2 grammatical gender, for decades linguists have noted that L2 learners demonstrated the use of a default gender. In the results of their studies mentioned above, Hawkins (1998) and Bruhn de Garavito and White (2000) indicated that L2 learners were assigning a default gender to nouns. However, the default gender was not uniformly assigned as masculine or feminine. The following studies have come to similar conclusions.

Finnemann (1992) analyzed the speech of three first year university students over a six month period. The task consisted of nine semi-guided interviews in intervals of two-three weeks. His results showed similarities to Hawkins' (1998) and Bruhn de Garavito and White's (2000) studies where the masculine form was used as a default gender. In addition, he noted students performed best with self and human female referents, while with human referents, such as persona (person) they used the masculine form; and adjective gender agreement was acquired later than articles.

Fernández-García (1999) studied the speech of seven L2 Spanish university students with L1 English. In a semi-guided interview conducted at the beginning of the semester, students were asked general questions pertaining to their lives and activities. Her results revealed similarities to Finnemann (1992), where gender assignment of articles was established earlier than adjective agreement; there was more accuracy with nouns ending in - $o$ and $-a$ morphemes; in some cases, subjects changed endings of certain nouns to agree with the article; and errors were consistent in deceptive nouns such as la problema.

Alarcón (2004) studied sixty-nine L1 English speaking learners of four different levels of university Spanish. The task involved a two-part written test to examine both gender assignment and agreement. In the first part, students were given a list of 24 nouns and were asked to write the correct definite article, which would test gender assignment. In the second part, twelve situations were described and the students were asked to write an appropriate adjective based on the context of the description. Alarcon found that the three lower-levels of L2 learners tended to overuse a masculine gender form with natural gender feminine nouns; whereas the students from the fourth level showed more feminine gender forms with masculine nouns. 
In summary, many researchers analyzing gender assignment and agreement of L2 with different L1 backgrounds, i.e. L1 with grammatical gender versus L1 without, have reported similar results suggesting that whatever is happening, it is not merely an L1 effect (Dewaele \& Veronique 2000 and Fernández-García 1999). Researchers such as Epstein, Flynn and Martohardjono (1996); Schwarz and Sprouse (1994 and 1996) and White (1989) believe that learners are not restricted to L1 constraints as Clahsen and Muysken's (1989) no parameter setting hypothesis suggests..

\subsection{The bilingual speaker versus the heritage speaker}

The term heritage speaker refers to an individual whose L1, which is usually spoken at home, is different from that spoken by the majority of the people in a particular country. Valdés (1995) uses the term heritage speaker for individuals whose L1 acquisition was incomplete or interrupted because of early onset of the L2.

In earlier studies, the language of the heritage speaker was addressed within the confines of bilingualism (Lipski, 1993; Anderson, 1999); and although today this is still observed, researchers are focusing more on the language of the heritage speaker in regard to L1 and L2 acquisition. Given that the present study concentrates on the errors and error patterns of gender assignment and agreement of heritage speakers and second-language learners, the following discussion will address the current research on this topic.

Lipski (1993) conducted oral interviews with 45 informants from the Houston area. They were equally divided into three groups: fluent Spanish speakers/bilingual, transitional bilingual speakers or vestigial Spanish speakers, and Anglo-American learners of Spanish as a second language ${ }^{1}$. Lipski identified the incorrect usage of inflectional morphemes for gender and number with noun/adjective agreement. In his findings, he stated that in this particular aspect (1993: 161): «the vestigial Spanish speakers are aligned more with the second language learners.»

In a longitudinal study of two bilingual English-Spanish children, Anderson (1999) set out to analyze L1 attrition patterns in gender agreement, where one child was a little over six years old and the other barely four at the onset of the two year study. Her results showed a difference over time between both subjects. The older child showed more fluctuation of gender agreement across time with few errors, but did not overgeneralize the use of any specific gender. The younger child, however, showed fluctuation of gender agreement early on, and the errors progressively increased to a masculine default form for all nouns. Anderson attributed these results to decreased input of the L1, possible sociolinguistic factors, and possible unstable linguistic competence.

${ }^{1}$ Lipski's term vestigial bilingual addresses those speakers of a minority language in contact with the national language. He defines this group «as a transitional group of speakers who spoke their L1 during childhood, but have subsequently lost their native ability» (1993: 157). He distinguishes this group from the true transitional bilingual, which he defines as speakers «who never learned a full form of the language» (1993: 157). Lipski (1993: 58-59) provides criteria to define the vestigial or transitional bilingual: «1) little or no school training in Spanish; 2) Spanish spoken in earliest childhood either as the only language in the home or in conjunction with English; 3) a rapid shift from Spanish to English occurred before adolescence; 4) subsequent use of Spanish is confined to conversation with few relatives; 5) when addressed in Spanish by bilingual speakers, they will answer wholly or partially in English; and 6) they have no strong identification with the Spanish language.» 
With the latest research on bilingual speakers, some linguists have begun to focus on the effects that L2 inception age may have on L1 grammar incompleteness, particularly when the latter is a minority language in a dual-language environment (Montrul, 2004a and 2005; Zaretsky and Bar-Shalom, 2008; and Polinsky, 2008).

Zaretsky and Bar-Shalom (2008) analyzed agreement, lexical and case errors in RussianEnglish bilinguals (10 children and 10 adults) with varying lengths of exposure to the L2 (English). The subjects were either born in the United States or brought there at an early age. The two tasks required for this study were to listen to a sentence in Russian and determine if the sentence was correct or incorrect; and to narrate a story based on a series of pictures. The performance of each group in each task was compared and analyzed for errors. The results indicated that with the children there was a strong correlation between gender errors in the narratives and lexical errors on the first task; the adult speakers' errors, however, were fewer. Zaretsky and Bar-Shalom affirmed previous research in the area of L1 attrition, adding that the longer the exposure to the L1 the greater the likelihood to acquire the grammatical system (Seliger \& Vago, 1991; De Bot, 2001; and Jia \& Aaronson, 2003).

In another study, Montrul and Potowski (2007) analyzed Spanish gender assignment and agreement of nouns in the spoken language of monolingual, bilingual, and L2 learners between ages 6 and 11. Children were asked to complete two tasks. The first task elicited noun phrases with determiners. Subjects were shown colored pictures of Little Red Riding Hood and then they were asked to narrate the story. The second task, which elicited adjective agreement, was a three-piece puzzle card game with colored animals and numbers. The authors set out to analyze gender of the L1 as it related to age and length of exposure to the L2 English in a dual immersion school setting. Their results indicated that the monolingual children were always accurate in both tasks; while the other groups demonstrated some differences between the two task-types. In the narrative task, both groups of bilingual speakers, sequential bilinguals (heritage speakers who acquired Spanish first and English later in school) and simultaneous bilinguals (heritage speakers who acquired and used both Spanish and English since their early childhood), with no difference between them, performed better than the L2 learners who had many more errors. Conversely, in the second task which addressed adjective agreement, the sequential bilinguals provided more accuracy than the simultaneous bilinguals who did not differ from the L2 learners. The final result of this study found that all of the groups were more accurate with masculine gender forms than with feminine gender markings in both tasks.

A growing number of studies comparing L1 acquisition of the heritage speaker to L2 acquisition of the learner of Spanish have revealed some similarities (Montrul, Foote and Perpiñán, 2008 and Polinsky, 2008). Montrul (2006) views acquiring a heritage language as both similar to and different from L1 and L2 acquisition, while Polinsky (2008: 40) believes that the heritage language «provides a crucial missing link between competent L1 learners, balanced bilinguals, and possibly L2 learners.»

In an extensive study on gender agreement in L2 learners and heritage speakers of Spanish, Montrul, Foote and Perpiñán (2008) considered the effects of age on language acquisition. They analyzed the speech, written comprehension and written recognition of 69 heritage speakers, 72 L2 learners and 22 native Spanish speakers to observe any differences of gender agreement in noun phrases and the types of errors in adult L2 learners and heritage speakers of a similar proficiency level. In addition, they tested proficiency levels of their subjects. Out of the three different experiments conducted, the one related to this study is the 
third, which addressed oral language. Subjects were shown photographs of people, animals and objects including animate and inanimate canonical nouns, nouns ending in -e or a consonant, and nouns with gender exception. They were asked to identify what they saw in each picture by providing an indefinite determiner, the noun and an adjective (veo un/una Noun +Adjective). The results indicated that the heritage speakers were more accurate than the L2 learners. However, the types of gender errors provided by each group were similar, as well as their preference for the default masculine form versus the feminine gender marker.

Polinsky (2008) analyzed gender assignment of twelve American Russian heritage speakers at university undergraduate or graduate level. All participants, with the exception of three, were born in the United States to Russian speaking families. Three of the participants were born in Russia, moved to the United States between ages 3 and 5 and stopped speaking Russian between ages 4 and 7. Five monolingual speakers were also used for the control group. Participants were given two different tasks, one with controlled production to test gender, and another to test comprehension. The results of the first experiment indicated that gender for both masculine and feminine nouns ending in a vowel did not cause any problems; however neuters, stem-stressed neuters and feminine nouns ending in a palatalized consonant, did. Some of the participants reduced the three gender system to two. Polinsky (2008:55) stated that «heritage speakers have difficulty with the same classes as uninterrupted L1 learners.» In the second experiment, the heritage speakers demonstrated problems with feminine nouns. The pattern appeared to be assigning neuters as feminine nouns. In this experiment, Polinsky found that there was more variation than in the first experiment. She (2008: 63) concluded that «the errors made by heritage speakers overlap with errors made by L1 learners of Russian, but are not exactly the same in nature. It is possible that heritage speakers reanalyze the system based on their limited input, and the results of this reanalysis are not the same as in emergent systems of L1 learners.»

In summary, these studies demonstrated types of error patterns with grammatical gender markings when comparing different groups of bilingual and heritage speakers. In addition, some of these errors led researchers to compare possible similarities between L1 and L2 acquisition, and the effect that age of L2 inception or the lack of L1 acquisition completeness may have on these groups. The discussion of all these previous studies brings us to the present research.

\section{Research Questions}

Research has shown that acquiring grammatical gender in L1 or L2 presents difficulties; similar patterns between heritage speakers and L2 learners have motivated the following research questions for the present study:

1. Are there differences in the number of gender assignment and agreement errors between the three different groups?

2. Are there differences in the error patterns of gender assignment and agreement provided by three groups of participants?

The motivation for this study came from observations of data collected from first and second generation heritage speakers, which prompted additional data collection from secondlanguage learners of Spanish. In the initial observations, evidence of similarities in the errors 
provided by the three groups led to the hypothesis that L2 learners and heritage speakers suffer similar consequences of language incompleteness.

\section{Methods}

This paper was based on data collected from heritage speakers of Spanish in the United States and second language learners of Spanish. The participants were randomly selected from different high schools throughout the United States that were willing to take part in the study. The heritage speakers were randomly selected from a corpus of participating students from areas throughout the United States with large Hispanic populations. The study was later administered to second language learners from an area with little to no Spanish exposure in the community.

\subsection{Participants}

There was a total of forty-four participants: sixteen first generation heritage speakers (herein referred to as HS1 speakers), fourteen second generation heritage speakers (herein identified as HS2 speakers), and fourteen second language learners (herein known as SLL). The classification of the heritage speakers was based on their parents' background: 1) the parents of HS1 participants were born in a Spanish speaking country, spoke little or no English, and Spanish was the dominant language at home; and 2) the parents of HS2 participants were born in the United States and spoke English, but Spanish was the dominant language at home.

All of the heritage speakers were born in the United States and attended schools that provided them with either bilingual education programs or Spanish as a class subject. Table 1 shows the distribution of HS1 and HS2 participants:

Table 1. Distribution of Heritage Speakers.

\begin{tabular}{|lcc|}
\hline & HS1 & HS2 \\
Albuquerque, New Mexico & 0 & 2 \\
Amsterdam, New York & 3 & 0 \\
Carson City, California & 1 & 0 \\
Chico, California & 0 & 3 \\
Laredo, Texas & 0 & 2 \\
Miami, Florida & 2 & 0 \\
New York City, New York & 4 & 0 \\
Perth Amboy, New Jersey & 3 & 3 \\
San Antonio, Texas & 3 & 4 \\
\hline
\end{tabular}

The SLL speakers had between four and five years of Spanish studies and were in Advanced Placement classes in their high schools. Most of them were natives to the area with little travel experience outside of the state, and with little to no exposure to the Spanishspeaking world outside of the classroom. 
All three groups were high school students between grades nine and twelve, and they were all educated from first grade, age six, in schools throughout the United States.

\subsection{Materials and procedures}

As part of the interview process, participants were asked to fill out a sociolinguistic questionnaire. The heritage speakers and the second language learners were provided slightly different questionnaires that inquired about their backgrounds in both Spanish and English, and the language they used most in different domains.

The sociolinguistic questionnaire for the HS1 and HS2 participants requested language use information to assess the frequency of Spanish versus English, and background information on both their parents and themselves. The SLL participants' questionnaire requested information about L2 language exposure inside and out of the classroom.

The materials used to conduct the interviews were two sets of six drawings with social settings (e.g. scenes in offices, schools, on the street, or at home), each with an accompanying questionnaire. The situations in each set provided similar scenes and questions; and the set of drawings selected for each participant was random. Participants were asked to name the items seen in each picture (Dime que ves en el dibujo 'Tell me what you see in the drawing') and to recount personal experiences that each scene triggered (e.g. Cuéntame de una experiencia interesante que recuerdas cuando estuviste en la escuela. 'Tell me about an interesting experience you remember about when you were in school'). The speech elicited was natural and informal. The twenty-five minute interviews were conducted and recorded in an informal setting at the different participating schools. These were then transcribed and analyzed for varying patterns. The data extracted for observation included only those nouns and adjectives with gender markings, that is, those with inflectional morphemes or a determiner that would provide gender information (e.g. the article).

\section{RESUlts AND Discussion}

This section presents the results and discussion from the sociolinguistic questionnaire as well as the study itself.

The results of the sociolinguistic questionnaire for the HS1 and HS2 speakers indicated the following: 1) based on information about their parents, the participants were first or second generation Hispanics in the United States; 2) they were from middle class families; 3) Spanish was the dominant language spoken at home, in the neighborhood, and with relatives and friends; and 4) English was the dominant language for school, and listening and reading input (e.g. reading materials, television and radio). When asked to rate their Spanish speaking ability, they all rated it as native-like. The SLL participants' questionnaire provided the following information: 1) they learned Spanish exclusively in a classroom setting with no outside exposure to the language; 2) they had studied 4-5 years of Spanish in school; 3) none of them had ever resided in a Spanish-speaking country or community; and 4) none of them had a Hispanic background.

The results of this study presented a total of 3,679 Spanish noun tokens. The SLL group provided the greatest number of noun tokens with 1,674; followed by the HS1 group with 
1,148; and with the fewest noun tokens, 857 , the HS2 group. These nouns were subdivided and analyzed for article determiners and adjectives. Within this data, there were a total of 2,426 article tokens and 287 adjective tokens with inflectional gender markers (see Table 2 for distribution among groups).

Table 2. Distribution of Total Number of Tokens among Three Groups of Participants.

\begin{tabular}{|l|l|l|l|l|}
\hline Participants & $\begin{array}{l}\text { HS1 } \\
(\mathrm{n}=16)\end{array}$ & $\begin{array}{l}\text { HS2 } \\
(\mathrm{n}=14)\end{array}$ & $\begin{array}{l}\text { SLL } \\
(\mathrm{n}=15)\end{array}$ & $\begin{array}{l}\text { Total } \\
(\mathrm{n}=45)\end{array}$ \\
\hline $\begin{array}{l}\text { Total Number of } \\
\text { Noun Tokens }\end{array}$ & 1,148 & 857 & 1,674 & 3,679 \\
\hline $\begin{array}{l}\text { Total Number of } \\
\text { Article Tokens }\end{array}$ & 762 & 570 & 1,094 & 2,426 \\
\hline $\begin{array}{l}\text { Total Number of } \\
\text { Adjective } \\
\text { Tokens }\end{array}$ & 99 & 85 & 103 & 287 \\
\hline
\end{tabular}

\subsection{Error patterns}

Given that the focus of this study addresses error patterns of noun gender assignment and agreement, only nouns with articles and gender marked adjectives were examined. For example, the adjective rojo (red) has this masculine form and a feminine form roja; whereas verde (green) does not have a distinctive gender form and consequently these adjectives were not addressed in this study.

From the data collected, the two categories to be discussed in this study are article/noun assignment and noun/adjective agreement.

\subsubsection{Article/noun gender assignment errors}

There were 2,426 article tokens present in the data (see Table 2 above). In this category, there were a total of 161 gender assignment errors. Although this category provided the largest number of errors, these were $6.75 \%$ of the total number of article determiner tokens (161 out of 2,426 article tokens) present in the data. The results, as seen in Table 3, indicated that the SLL group provided $122(75.75 \%)$ of these errors; followed by the HS2 group with 27 (16.75\%); and the HS1 group with 12 (7.5\%). 
Table 3. Total Number of Article/Noun Gender Assignment Errors and Types.

\begin{tabular}{|l|c|c|c|c|c|c|c|c|}
\hline & \multicolumn{2}{|c|}{ HS1 } & \multicolumn{2}{c|}{ HS2 } & \multicolumn{2}{c|}{ SLL } & \multicolumn{2}{c|}{ Total } \\
\hline & $\mathbf{n}$ & $\%$ & $\mathbf{n}$ & $\%$ & $\mathbf{n}$ & $\%$ & N & $\%$ \\
\hline $\begin{array}{l}\text { Article/Noun } \\
\text { Errors }\end{array}$ & 12 & 7.5 & 27 & 16.75 & 122 & 75.75 & 161 & 6.75 \\
\hline $\begin{array}{l}\text { Masc. Article/ } \\
\text { Fem. Noun }\end{array}$ & 9 & 5.5 & 15 & 9.25 & 86 & 53.5 & 110 & 68.5 \\
\hline $\begin{array}{l}\text { Fem. Article/ } \\
\text { Masc. Noun }\end{array}$ & 3 & 2 & 12 & 7.5 & 36 & 22.25 & 51 & 31.5 \\
\hline
\end{tabular}

The type of gender error examined most was a masculine article with a feminine noun with $110(68.5 \%$ of the total 161 article token errors) occurrences. The distribution of this error type among the three groups of speakers was the following: HS1 had $9(5.5 \%)$ occurrences; HS2 had 15 (9.25\%) inaccuracies; and SLL had 86 (53.5\%) errors (see Table 3). The results in this category reaffirm some of the findings of the previous research mentioned earlier in this study. The common use of the masculine article (el/los 'the' singular and plural, un 'a' or 'an', or unos 'some') with most nouns may indicate a tendency for gender reduction leading toward the elimination of distinctive gender agreement markers or simplification due to language in contact. In two different studies, linguists propose certain strategies for language acquisition in a language contact situation. Gutiérrez and Silva-Corvalán (1993: 75-76, originally defined in Silva-Corvalán, 1991) suggest three strategies that bilingual speakers, as well as second language learners, learn to address differences between their L1 and their L2: 1) transfer, where the developing language receives forms from another; 2) negative transfer, where there is loss of grammatical categories that exist in one language, but not in the other; and 3) simplification, where there is a generalization of rules leading to possible loss of certain forms in the minority language. In another study, Isurin (2005: 1116) suggests that «the bilingual may create a new rule for L1 in those areas of the L1 grammar where the L2 rule is less marked in some ways.» These studies seem to speak to the results observed in the present study, whereas frequently, the masculine modifier appears as the default gender.

The data for the article/noun gender agreement markers showed varied patterns of masculine article/feminine noun errors that merit discussion. First, all three groups supplied examples where the feminine nouns were systematic with one of the common grammar rules (i.e. most nouns ending in $-a$, and all nouns ending in -tad,-dad,-tud, -ción, and -sión are feminine), but they were accompanied by a masculine article. Here are some cases from the data: el semana 'the week' (SLL); los personas 'the people' (SLL); el escuela 'the school' (SLL \& HS2); un inyección 'the injection' (SLL \& HS2); un pelota 'the ball' (SLL); los direcciones 'the directions' (SLL \& HS2); los cosas 'the things' (HS1); un cabra 'a goat' (HS1); and un multitud 'a multitude' (HS1). What is especially interesting in these examples, are those nouns ending in the inflectional morpheme $-a$. Second language learners are exposed to the rule of nouns ending in ' $-a$ ' are feminine early on in language acquisition. Second, worthy of mention 
are those nouns provided only by the SLL and HS2 groups when there was a human referent: un madre 'a mother' (SLL); un niña 'a girl' (SLL); and el maestra 'a teacher' (HS2). The general rule indicates these nouns have a natural gender. Third, there were two occurrences of el/un vez 'the/a time' (SLL \& HS1) instead of la/una vez. This may have occurred because most nouns ending in $-z$ are masculine. Finally, other occurrences in all three groups included el calle 'the street' (SLL \& HS2) or los más clases 'the other classes' (HS1) where there were no overt gender markings.

The errors of feminine article/masculine noun showed fewer gender-agreement inaccuracies overall. However all three groups demonstrated examples of this error type also. Here, the error patterns were with nouns ending in $-o,-n,-r,-z$, which based on the basic grammar rule are mostly masculine: la cuarto 'the room' (SLL \& HS2); una juego 'a game' (HS2); and las tenedores 'the forks' (HS1). There were several patterns triggered by words of Greek origin, such as la mapa 'the map' (HS1) and la dia 'the day' (SLL). Considering these are exceptions to the more basic grammar rule, this gender error may have been the result of applying the general rule or the incomplete acquisition of learning the exceptions.

Two interesting observations were made concerning the noun agua (water). With SLL and HS2 speakers, agua (water) appears with the feminine article la (the). Although it is a feminine noun, as explained earlier, initial $a$ - nouns, are accompanied by the masculine article el/un (the/a) in the singular form for phonological reasons. This is a specific rule that learners acquire at a higher level of proficiency, therefore this inaccuracy may once again be the result of applying the general rule or not acquiring the exceptions. By supplying the feminine article $l a$, it is apparent that the speakers were aware that agua (water) is a feminine noun. Other examples were observed with the HS1 speakers, where they supplied a contraction of the article, l'agua (the water). In a study conducted by García (1998) on Spanish in the Southwest, she found this phenomenon to be common. These examples in the current study reaffirm her findings, since the participants presenting these cases were from the Southwest.

\subsubsection{Noun/adjective gender agreement errors}

There were 287 adjective tokens reflecting gender agreement markers collected from the speech of all three groups of speakers. The distribution of adjectives from each group can be seen in Table 2 (see above).

A total of 59 (a little over $20.5 \%$ of the 287 total number of adjectives collected) noun/ adjective gender inaccuracies were apparent in the data (see Table 5): 5 from HS1; 9 from HS2; and 45 from the SLL speakers. 
Table 4. Noun/Adjective Gender Agreement Errors and Types.

\begin{tabular}{|c|c|c|c|c|c|c|c|c|}
\hline & \multicolumn{2}{|c|}{$\underline{\text { HS1 }}$} & \multicolumn{2}{|c|}{$\underline{\mathrm{HS2}}$} & \multicolumn{2}{|c|}{$\underline{\text { SLL }}$} & \multicolumn{2}{|c|}{ Total } \\
\hline & $\mathrm{n}$ & $\%$ & $\mathbf{n}$ & $\%$ & $\mathrm{n}$ & $\%$ & $\mathbf{N}$ & $\%$ \\
\hline $\begin{array}{l}\text { Noun/Adjective } \\
\text { Errors }\end{array}$ & 5 & 8.5 & 9 & 15.25 & 45 & 76.25 & 59 & 20.5 \\
\hline $\begin{array}{l}\text { Fem. Noun/ } \\
\text { Masc. Adjective }\end{array}$ & 3 & 5 & 8 & 13.5 & 29 & 49.25 & 40 & 67.5 \\
\hline $\begin{array}{l}\text { Masc. Adjective } \\
\text { /Fem. Noun }\end{array}$ & 2 & 3.5 & 1 & 1.75 & 16 & 27.25 & 19 & 32.5 \\
\hline
\end{tabular}

The type of noun/adjective gender agreement errors was mostly a feminine noun with a masculine adjective $(67.5 \%)$. As seen in Table 5, out of 40 errors of this type, the HS1 group offered 3 (5\%); HS2 participants supplied 8 (13.5\%); and SLL speakers provided 29 (49.25\%).

The gender agreement errors observed included varying examples. One was with a human referent, which appeared in both SLL and HS1 groups: una niña solo 'a girl alone' (SLL) and la familia junto 'the family together' (HS1). Another, in all three groups was feminine nouns ending in -a: lámpara rojo 'red lamp' (SLL), las plantas bonito 'the pretty plants' (HS1) or manzanas rojos 'red apples' (HS2). The third was with nouns with feminine morphemes, for example, las direcciones malos 'bad directions' or ciudad largo 'large city' (SLL). The fourth case, provided by HS2 participants, did not have an overt gender marker: la calle mal (the wrong street), or la luz rojo (the red light). Some of these tokens exhibit interesting patterns in that the speakers supplied a gender-appropriate article (la luz rojo 'the red light'); however the adjective agreement was incorrect. This shows the speakers' awareness of noun gender. These results support Finnemann (1992) and Fernández-García's (1999) findings that adjectives are acquired later than articles. To support a rationale for these errors among the heritage speakers, Lipski (1999) found that early childhood heritage speakers, which he identified as transitional bilinguals, may not have learned their L1 completely leaving them to provide similar errors as L2 learners of Spanish. Montrul (2004b) reaffirmed this in her study on second language acquisition and first language loss, where she found that gender agreement errors of early childhood heritage L2 speakers were similar to those of second language learners of Spanish because of incompleteness of language acquisition and lack of input in Spanish.

There were 19 (32.5\%) masculine noun/feminine adjective gender-agreement errors. Most of these were supplied by the SLL speakers (see Table 5).

Some of the error patterns were similar to those mentioned above. The speakers provided a correct gender marked article, indicating their awareness of the noun's gender; but they supplied an incorrectly marked adjective: el maestro enojada 'the angry teacher' (HS2) or el niño buena 'the good boy' (SLL). This again, is consistent with the findings of previous studies (Finnemann, 1992 and Fernández-García’s, 1999). The other examples of errors were provided by the SLL speakers. These included nouns without overt gender markers, (fútbol americana 
'football'); or nouns with human referents (ellos están aburridas 'they are bored'); and nouns ending in -o (la misma tiempo 'the same time'). This last example is consistent with some previous findings (Bruhn de Garavito and White, 2000; Fernández-García, 1999; and others) where some participants preferred the use of a feminine form and used it exclusively, making the feminine gender marking a default form.

\section{Conclusions}

Throughout this study, the two research questions posed at the beginning were taken into consideration. After analyzing the data, the results revealed that: 1) there was indeed a difference in the number of gender assignment and agreement errors between the three groups of Spanish speakers; and 2) there were similarities in the types of errors observed.

As seen in Figure 1, based on the total number of gender assigned noun tokens in each group, the SLL speakers provided 14\% (167 errors out of a total of 1,197 gender assigned modifier/noun tokens); the HS2 speakers supplied almost 5.5\% (36 errors out of a total of 669 gender assigned modifier/noun tokens); and the HS1 speakers offered the least amount with less than $2 \%$ (17 errors out of a total of 847 gender assigned modifier/noun tokens).

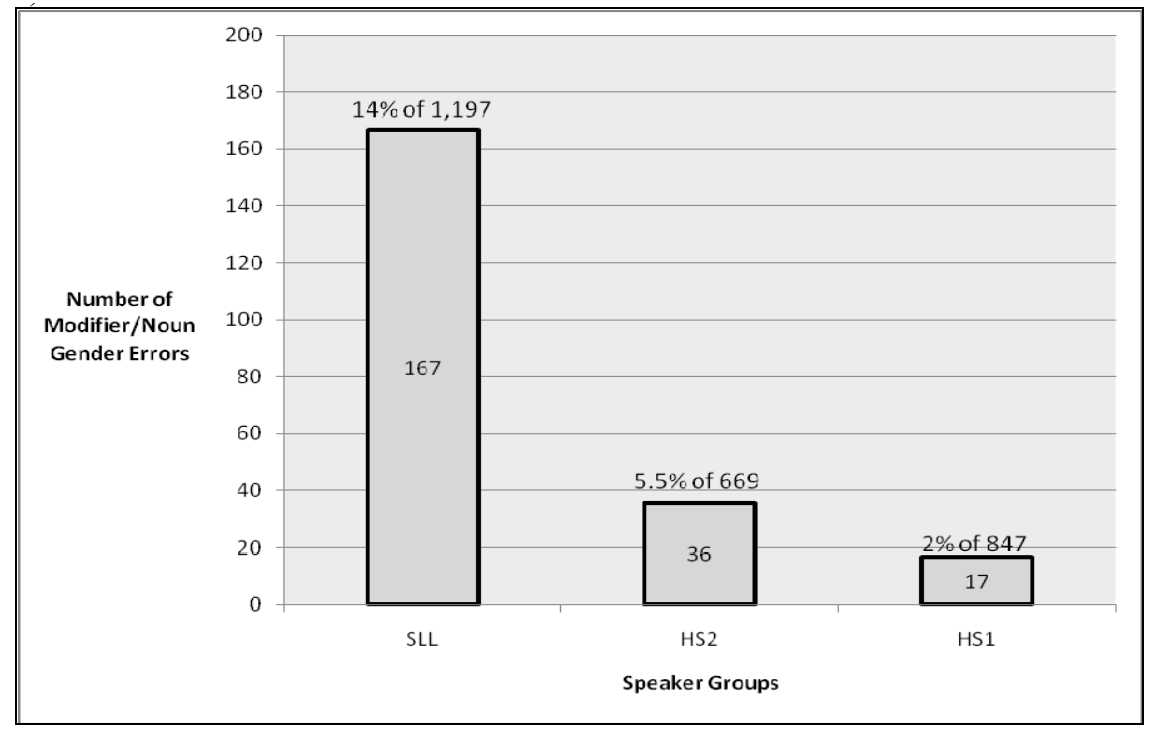

Figure 1. Gender Errors

It is not surprising that these percentage differences between the three groups are minimal, since all participants were born in the Unites States and educated in English speaking schools since age six. What may account for the minor differences between these groups is the amount of Spanish input they had. In one of her studies, Montrul (2004b: 275) suggested that both L2 
learners of Spanish and early childhood L2 learner heritage speakers demonstrate an incompleteness in language acquisition; and reduced language input during childhood for heritage speakers may lead to incomplete grammar acquisition.

In the present study, the SLL speakers, with L1 English, acquired Spanish strictly in the setting of an L2 classroom with no outside exposure to the language. In the case of the HS2 speakers, their parents were born in the United States, leaving them one generation removed from their L1 Spanish. These speakers may have had less input than the HS1 group, whose parents came from Spanish speaking countries. Although information about exposure to Spanish was collected on the sociolinguistic questionnaire, this paper did not focus on this topic and therefore these suggestions are speculative.

Concerning the second research question, two observations were made. First, the results showed that with all three groups, one of the most consistent errors observed was the use of a masculine modifier with a feminine noun, suggesting a masculine default form for most speakers. However, all three groups also presented some instances of errors with a feminine modifier and masculine noun. Most previous studies on gender agreement have identified the masculine form as a default gender with nouns and their modifiers in second language learners; but some also found the feminine form used either exclusively or as a strategy of overgeneralization in a number of their participants (Andersen, 1984 and Boyd, 1975).

The second observation concerning the second research question was that overall the three groups demonstrated a greater percentage of errors in gender agreement between noun/ adjectives than they did with article/nouns (see Figure1). This confirms Finnemann's (1992) and Fernández-García's (1999) findings that adjective agreement is acquired later than articles. However, observing the individual groups of speakers, there were some differences with the HS2 and SLL speaker groups. The HS2 group provided a slightly higher percentage of article/ noun assignment errors (16.75\%) than noun/adjective agreement errors (15.75\%). The SLL group, however, supplied about the same percentage of errors in each of these categories: $75.75 \%$ article/noun assignment errors versus $76.25 \%$ noun/adjective agreement errors.

In summary, the results of this study reinforce the findings of the numerous works discussed in this paper (Boyd, 1975; Andersen, 1984; Hawkins, 1998; Bruhn de Garavito and White, 2000; Finnemann, 1992; Fernández-García, 1999; Alarcón, 2004; Montrul, Foote and Perpiñán, 2008 and Polinsky, 2008). Although second language learners of Spanish provided more errors in gender assignment and agreement than the heritage speakers, the types of errors provided by these groups were similar.

\section{REFERENCES}

Alarcón, I. (2006). The second language acquisition of Spanish gender agreement: The effects of linguistic variables on accuracy. Munich: LINCOM.

Andersen, R. W. (1984). "What's gender good for anyway?", en R. W. Andersen (ed.), Second Language: A Cross-Linguistic Perspective. Rowley, MA: Newbury House, 77-99.

Anderson, R. T. (1999). "Loss of gender agreement in L1 attrition: Preliminary results", en Bilingual Research Journal, 23, 4: 389-408.

Boyd, P. A. (1975). "The development of grammar categories in Spanish by Anglo children learning a second language", en TESOL Quarterly, 9, 2: 125-135. 
Bruhn de Garavito, J. y White, L. (2000). "The second language acquisition of Spanish DPs: The status of Grammatical features", en A. T. Pérez-Leroux y J. Muñoz Liceras (eds.), The Acquisition of Spanish Morphosyntax: The L1/L2 Connection. Dordrecht: Kluwer Academic Publishers, 153-178.

Clahsen, H. y Muysken, P. (1989). "The UG Paradox in L2 Acquisition”, Second Language Research, 5: $1-29$

De Bot, K. (2001). "Language use as an interface between sociolinguistic and psycholinguistic processes in language attrition and language shift", en J. Klatter-Folmer y P. Van Avermaet (eds.), Theories on maintenance and loss of minority languages: Towards a more integrated explanatory framework. Münster: Waxmann, 65-82.

Dewaele, J. M. y Véronique, D (2000). "Relating gender errors to morphosyntax and lexicon in advanced French interlanguage", en Studia Linguistica 54: 212-24.

Epstein, S. J., Flynn, S. y Martohardjono, G. (1996). "Second Language Acquisition: theoretical and experimental issues in contemporary research", en Brain and Behavioral Science, 19: 677-758.

Fernández-García, M. (1999). "Patterns of gender agreement in the speech of second language learners", en J. Gutiérrez-Rexach y Fernando Martínez-Gil (eds.), Advances in Hispanic Linguistics: Papers from the $2^{\text {nd }}$ Hispanic Linguistics Symposium. Somerville, MA: Cascadilla Press, 3-15.

Finnemann, M. D. (1992). "Learning Agreement in the Noun Phrase: The Strategies of Three FirstYear Spanish Students", en International Review of Applied Linguistics in Language Teaching, 30, 2: 121-136.

García, M. E. (1998). "Gender marking in a dialect of southwest Spanish", en Southwest Journal of Linguistics, 17, 1: 49-58.

Gutiérrez, M. J. y Silva-Corvalán, C. (1993). "Spanish clitics in a contact situation", en A. Roca y J. M. Lipski (eds.), Spanish in the United States: Linguistic Contact and Diversity. New York, NY: Mouton de Gruyter, 75-89.

Hawkins, R. (1998). "Explaining the difficulty of gender attribution for speakers of English", paper presented at EUROSLA 8, Paris.

Hawkins, R. y Chan, Y. C. (1997). "The partial availability of Universal Grammar in second anguage acquisition: the 'failed features' hypothesis", en Second Language Research, 13: 187-226.

Isurin, L. (2005). "Cross linguistic transfer in word order: Evidence from L1 forgetting and L2 acquisition”, en J. Cohen, K. T. McAlister, K. Rolstad y J. MacSwan (eds.), Proceedings from the $4^{\text {th }}$ International Symposium on Bilingualism. MA: Cascadilla Press, 1115-1130.

Jia, G. y Aaronson, D. (2003). "A longitudinal study of Chinese children and adolescents learning English in the United States", en Applied Psycholinguistics, 24: 131-161.

Karmiloff-Smith, A. (1979). "Micro- and macro-developmental changes in language acquisition and other representational systems", en Cognitive Science, 3, 2: 91-118.

Müeller, N. (1994). "Gender and Number agreement within DP”, en J. M. Meisel (ed.), Bilingual first language acquisition: German and French. Philadelphia, PA: John Benjamins, 53-88.

Lipski, J. M. (1993). "Creoloid phenomena in the Spanish of transitional bilinguals", en A. Roca y J. M. Lipski (eds.), Spanish in the United States: Linguistic Contact and Diversity. New York, NY: Mouton de Gruyter, 155-173.

Montrul, S. (2002). "Incomplete acquisition and attrition of Spanish tense/aspect distinctions in adult bilinguals", en Bilingualism: Language and Cognition, 5, 1: 39-68.

Montrul, S. (2004a). The Acquisition of Spanish: Morphosyntactic development in monolingual 
and bilingual L1 acquisition and adult L2 acquisition. Language acquisition and language disorders 37(serie). Philadelphia, PA: John Benjamins.

Montrul, S. (2004b). "Convergent outcomes in second language acquisition and first language loss", en M. S. Schmid, B. Köpke, M. Keijzer, y L. Weilemar (eds.), First Language Attrition: Interdisciplinary Perspectives on Methodological Issues. Philadelphia, PA: John Benjamins, 259-280.

Montrul, S. (2006). "Incomplete acquisition as a feature of bilingual and L2 grammars", en R. Slabakova, S. A. Montrul y P. Prévost (eds.), Inquiries in Linguistic Development: In honor of Lydia White. Philadelphia, PA: John Benjamins, 335-359.

Montrul, S. y Potowski, K. (2007). "Command of gender agreement in school-age Spanish-English bilingual children", en International Journal of Bilingualism, 11, 3: 301-328.

Montrul, S., Foote, R. y Perpiñán, S. (2008). "Gender Agreement in Adult Second Language Learners and Spanish Heritage Speakers: The Effects of Age and Context of Acquisition", en Language Learning, 58, 3: 503-553.

Pérez-Pereira, M. (1991). "The acquisition of gender: what Spanish children tell us", en Journal of Child Language, 18, 3: 571-590.

Polinsky, M. (2006). “Incomplete acquisition: American Russian”, en Journal of Slavic Linguistics, 14: $191-262$.

Polinsky, M. (2008). “Gender under Incomplete Acquisition: Heritage Speakers' Knowledge of Noun Categorization", en Heritage Language Journal, 6, 1: 40-71.

Sabourin, L. (2001). L1 effects on the processing of grammatical gender in L2", en S. Foster-Cohen y A. Nizegorodcew (eds.), EUROSLA Yearbook, 1: 159-69.

Schwarz, B. D. y Sprouse, R. (1996). "L2 cognitive states and the full transfer/full access model", en Second Language Research, 12: 40-72.

Seliger, H. W. y Vago, R. M. (1991). First language attrition. Cambridge University Press.

Silva-Corvalán, C. (1991). "Spanish language attrition in a contact situation with English", en H. W. Seliger y R. M. Vago (eds.), First language attrition: Structure and theoretical perspectives. Cambridge, UK: Cambridge University Press, 151-171.

Valdés, G. (1995). "The teaching of minority languages as academic subjects: Pedagogical and theoretical concerns", The Modern Language Journal, 79: 299-328.

White, L. (1989). Universal grammar and second language acquisition. Amsterdam; John Benjamins.

White, L., Valenzuela, E., Kozlowska-Macgregor, M, Leung, I y Ben Ayed, H. (2001). The status of abstract features in interlanguage: Gender and number in Spanish», en Proceedings of the $25^{\text {th }}$ Annual Boston University Conference on Language Development, 792-802

Zaretsky, E. y Bar-Shalom, E. G. (2008). "Is selective attrition possible in Russian-English bilinguals?", en International Journal of Bilingualism, 12, 4: 281-302. 